\title{
ESTUDIO DE ALGUNAS ESPECIES DE ASCOMICETES MACROSCOPICOS, DE LA FLORA ESPAÑOLA
}

\author{
J. M. LOSA QUINTANA \& L. FREIRE *
}

\section{RESUMEN:}

Se realiza el estudio de doce especies de Ascomicetes, cuyos cuerpos fructíferos alcanzan tamaños macroscópicos y de los cuales pudieron realizarse diapositivas directamente del natural o en el Laboratorio. De cada una de ellas se realiza un breve comentario de sus peculiaridades morfológicas o ecológicas. En algún caso pudo seguirse el desarrollo de sus fructificaciones. La revisión nomenclatural ha sido realizada por Moser, M.: Kleine Kryptogamen flora II a: Ascomyceten. Al menos dos especies de las que se muestran creemos son nuevas citas para la Flora española de Ascomicetes.

\section{SUMMARY:}

We study twelve species of Ascomycetes with ascocarps. We do a little comentary of their morfological and ecological peculiarities. The nomenclature review is according to Moser, M. in Gams: Kleine Kryptogamenflora II a. We think at last two species are new for Iberian Peninsula.

\section{INTRODUCCION}

En diversas excursiones han sido recolectados cuerpos fructíferos de Ascomycetes macroscópicos para realizar su determinación taxonómica. En la presente nota pretendemos mostrar la documentación de aquellas especies que han podido ser identificadas, entre las que hemos recolectado.

En casi todas ellas han sido realizados estudios sobre sus características macro y microscópicas, así como se ha procurado apreciar aquellos aspectos de su hábitat y modo de vida locales y datos precisos para su correcta identificación taxonómica. 
Sarcoscypha coccinea (Fr.) Lambotte

Plectania coccinea (Scop. ex Fr.) Fuckel

Los ejemplares estudiados muestran un desarrollo sobre restos lignificados de ramas de Quercus ilex L. subsp. ilex, procedentes de Sant Llorenç del Munt (Barcelona) en zonas a elevada altitud y humedad, en Febrero de 1970.

Los receptáculos de los ejempla res estudia dos son poco cupulados y cortamente estipitados mostrando una coloración rojo intensa. Exteriormente muestran una coloración blanco tomentosa y el borde marginal del apotecio muy ligeramente dentado. La carne muestra un tejido apretado, su zona interna formada por hifas laxamente. entrelazadas y la externa constituída porhifas de mayor diámetro, tabicadas, y con la membrana más refringente.

Las esporas son elípticas cilindráceas y variables en su forma. Su tamaño oscila entre 20,5-27,5 por 9-12,5 micras. La envoltura externa es lisa al microscopio óptico y su contenido permite a preciar granulaciones alrededor de una vacuola central. Parece que es más frecuente al comienzo de la primavera, su ecología es saprófita epixílica sobre diversas especies de Quercus.

Sepultaria summeriana (Cke.) Massee

S. sumneri (Bk.) Cke.

Campus Universitario de Santiago, sobre el suelo, bajo Cedrus atlantica. Aparición tanto primaveral como otoñal, mostrando gran número de carpóforos. Esta especie fue citada por Calonge (1976) y por nosotros (1978) en un estudio donde se mostraban diversos aspectos morfológicos de la misma.

Leptopodia elástica (Bull.) Boud.

Helvella elástica Bull. ex Fr.

Selva Negra de El Pedroso, Santiago de Campostela: O,ctubre de 1976, entre la hierba junto a un camino forestal. Especie probablemente micorrícica.

Diatripe disciformis (Hoffm.) Fr.

Sobre una rama de Fagus silvatica, recolectada en el Montseny (Barcelona). Es una de las especies de Ascomicetes más frecuentes sobre restos de leños de esta especie arbórea. Otoño 1971.

Xylaria hypoxylon (L. ex Fr.) Dumortier

Sobre restos lignificados de Fagus silvatica Hayedo de el Montseny (Barcelo-

na) Otoño de 1971. En su fase esporal.

Mitrula paludosa Fr.

M. phalloides Bull.

Selva Negra de El Pedroso, Santiago de Compostela sobre filodios de Eucaliptus que se encontraban sumergidos en el agua de un regato. 
Scutellinia scutellata (L. ex St. Amans) Lambotte var. cervorum Le Gal.

Selva Negra de El Pedroso, Santiago de Compostela, sobre restos lignificados en la braña de la entrada, Noviembre de 1976.

Destacan los apotecios provistos de largas cerdas que se insertan en su margen.

Xylosphaera hippotrichoides (Sowerby ex Fr.) Dennis

Sobre leño de Pinus, en un sótano húmedo; Lens-Negreira; Febrero de 1977.

Fueron realizados estudios de sus peculiaridades macro y microscópicas, pudiéndose apreciar tanto las esporas de tipo asexual, como las ascas y ascosporas.

Leotia lubrica Pers.

L. gelatinosa Hill.

Ejemplares recolectados en la cuenca media del río Eume cerca de Caaveiro (La Coruña). Octubre de 1976, en lugares muy húmedos en contacto con el cauce de un regato. Destaca la morfología de los cuerpos fructíferos.

Cordyceps militaris (L. ex St. Amans) Link

Santa Cruz de Rivadulla (La Coruña) Octubre de 1975. Ejemplares recolectados en el borde de un sendero en el pinar de repoblación próximo a dicha localidad. También en la Selva Negra de El Pedroso: Nov. 1976. Ejemplares muy típicos que se desarrollan sobre larvas de diversas especies de insectos.

Hymenoscyphus repandus (Phillips) Dennis

Ejemplares procedentes de la Selva Negra de El Pedroso Santiago de Compostela; Oct. 1976, sobre humus vegetal con elevada proporción de materia orgánica.

Cheilymenia coprinaria (Cooke) Boudier

Cheilymenia coprinaria Boud

Se muestran los apotecios sentados de reducido tamaño que forma esta especie, llegan hasta $5 \mathrm{~mm}$., de diámetro, su margen es ciliado, con peloscortos espaciados y de color pardo. La cara exterior es un poco más pálida que la interna. Siempre saprófita sobre estiércolo animal. 


\section{BIBLIOGRAFIA}

DENNIS, R.W. 1968: British Ascomycetes. Verlag V. Cramer, 1-455. 3.301 Lehre.

LOSA QUINTANA, J. M. 1974: Contribución al estudio de los Ascomicetes con apotecios de Cataluña. Collect. Bot. 9 (3): 45-60. Barcelona.

- \& FREIRE GARCIA L. 1978: Macromicetes de Galicia: Otoño 1975. Invierno 1976. Braña Bol. Soc. Gal. Hist. Nat. 1; 50-79. Santiago de Compostela.

MORENO, G.; CALONGE, F.D. \& DE LA TORRE, M. 1975: Estudio ecológico y descriptivo de algunos hongos interesantes. Bol. Est. Ecologia 4: (7): 35-50. Madrid.

MOSER, M. 1967: Ascomyceten in H. Gams Kleine Kryptogamenflora II, a Gustav F. Verlag, Stuttgart.

(Recibido el 15 de abril de 1979) 